\title{
Flavin Adenine Dinucleotide Synthetase 1 Is an Up- regulated Prognostic Marker Correlated With Immune Infiltrates in Breast Cancer
}

\section{Lei Zhang}

Sun Yat-sen University Cancer Center

Jia-Peng Deng

Sun Yat-sen University Cancer Center

Ru Tang

Sun Yat-sen University Cancer Center

Jia-Yuan Sun

Sun Yat-sen University Cancer Center

Feng Chi

Sun Yat-sen University Cancer Center

\section{San-Gang Wu}

The First Affiliated Hospital of Xiamen University

Zhen-Yu He ( $\square$ hezhy@sysucc.org.cn )

Sun Yat-sen University Cancer Center https://orcid.org/0000-0001-5777-382X

\section{Primary research}

Keywords: FLAD1, Breast Neoplasms, Prognosis, DNA Mismatch Repair, Tumor-Infiltrating

Posted Date: February 12th, 2021

DOl: https://doi.org/10.21203/rs.3.rs-196296/v1

License: (c) (i) This work is licensed under a Creative Commons Attribution 4.0 International License. Read Full License 


\section{Abstract}

Background: Flavin adenine dinucleotide synthetase 1 (FLAD1) is a prognostic biomarker in several cancers. This study aimed to identify its effect on survival and potential mechanism in breast cancer (BRCA).

Methods: We used the OncoMine, PrognoScan, and UALCAN databases and Kaplan-Meier Plotter to explore FLAD1 expression and survival prognosis in pan-cancer and BRCA. The LinkedOmics database, Gene Ontology-Biological Process (GO-BP), and the Kyoto Encyclopedia of Genes and Genomes (KEGG) pathways were used for co-expression analyses. The Tumor Immune Estimation Resource, Sangerbox online tools, and the Gene Expression Profiling Interactive Analysis database analyzed the relationship between FLAD1 and cancer immune infiltrates.

Results: FLAD1 expression was higher in tumor tissue than adjacent normal tissue in many cancers. Increased $F L A D 1$ expression was correlated with poor overall, relapse-free, and disease-free survival in BRCA. The KEGG pathway and GO-BP analyses showed that FLAD1 expression was correlated to the tRNA metabolic process and mitochondrial gene expression. The DNA mismatch repair (MMR) and methylation status indicated a potential BRCA metastasis mechanism. Immune infiltration was associated with MMR, improved BRCA prognosis, and was negatively associated with FLAD1 expression. High FLAD1 expression led to the down-regulation of macrophages and monocyte infiltration, which might relate to cancer metastasis.

Conclusions: FLAD1 expression is higher in BRCA than in normal tissue. High FLAD1 expression was associated with worse survival and might be associated with MMR pathway and immune infiltrations. These results suggest that FLAD1 could serve as a novel biomarker for prognosis and metastasis in BRCA.

\section{Background}

Breast cancer (BRCA) is one of the most common cancers and the primary cause of cancer-related mortality in females worldwide. Almost 268000 women are newly diagnosed with BRCA every year in the United States, and approximately $40000 \mathrm{die}^{1}$. Although we can predict the prognosis and guide clinical treatment of patients based on traditional clinicopathological factors and some other indicators identified in clinical practice ${ }^{2}$, more precise biomarkers are needed to help improve the diagnostic accuracy and prognostic prediction.

Flavin adenine dinucleotide synthetase 1 (FLAD1) is a vital protein-coding gene. It encodes the flavin adenine dinucleotide synthetase (FADS), a key enzyme that catalyzes adenylation of flavin mononucleotide (FMN) to form flavin adenine dinucleotide (FAD) coenzyme ${ }^{3}$. The FLAD1 gene is located on chromosome 1q21.3 and is widely expressed in human tissues, including the thyroid, lymph nodes, and breasts ${ }^{4}$. FAD, found in the cytoplasm and mitochondria, is an accessory factor responsible for transport in the mitochondrial dehydrogenase reaction. It is closely related to DNA phosphorylation and protein metabolism and is involved in nuclear redox activity that directly reprograms the chromatin structure and 
leads to dependent transcriptional activation or repression ${ }^{5}$. FAD imbalance might be an important cause for cell degeneration or tumorigenesis. Hence, FADS is important for tumor cell progression as it functions in the oxidation-reduction chain. In previous studies on other cancers, including prostate cancer ${ }^{6}$, nonsmall cell lung cancer ${ }^{7}$, and gastric cancer ${ }^{8}, F L A D 1$ expression was significantly associated with poor survival and prognosis. However, no study has explored the relationship between FLAD1 expression and BRCA.

This study evaluated the relationship between FLAD1 and BRCA patients' survival and searched for potential mechanisms, using public databases, including OncoMine, PrognoScan, Kaplan-Meier Plotter, LinkedOmics, Sangerbox online tools, Tumor Immune Estimation Resource (TIMER), and Gene Expression Profiling Interactive Analysis (GEPIA). Our study results shed light on the predictive value of FLAD1 in BRCA, suggesting a potential correlation and mechanism associating FLAD1 with BRCA prognosis and immune infiltration.

\section{Methods}

\section{The Expression of FLAD1 in Pan-Cancer in the OncoMine Database}

FLAD1 expression level in pan-cancer was analyzed in the OncoMine database with a $P$-value of 0.01 and a fold change of $1.0^{41}$.

\section{Survival Analysis in PrognoScan, Kaplan-Meier Plotter, and UALCAN Databases}

The relationship between FLAD1 expression and survival was analyzed in PrognoScan ${ }^{42}$ and KaplanMeier Plotter ${ }^{43}$. FLAD1 expression was searched in the microarray datasets of PrognoScan to determine its relationship with prognosis, including overall survival (OS), disease-free survival (DFS), and relapse-free survival (RFS). We set the significance threshold at a Cox $P$-value $<0.05$. Kaplan-Meier Plotter is a powerful online to assess the effect of 54000 genes on survival in 21 cancer types. We used it to analyze the relationship between FLAD1 expression and OS and RFS. Hazard ratios (HRs), 95\% confidence intervals ${ }^{44}$, and log-rank $P$-values were calculated. Different clinical characteristics and prognosis and their relationship with FLAD1 in BRCA were analyzed by the UALCAN database ${ }^{45}$.

\section{Co-expression Analysis of FLAD1 in LinkedOmics Database}

We analyzed the co-expression of $F L A D 1$ by the LinkedOmics database, which contains a large dataset from The Cancer Genome Atlas project ${ }^{46}$, with more than a billion data points ${ }^{47}$. We used the Spearman correlation coefficient and present the results in volcano plots and heat maps. We used the Function Module of the gene set enrichment analysis (GSEA) for kinase enrichment, miRNA, and transcription factor-target analyses in the Gene Ontology-Biological Process (GO-BP) and the Kyoto Encyclopedia of Genes and Genomes (KEGG) pathways. We used a false discovery rate $($ FDR $)<0.05$ as the rank criterion and performed 500 simulations. 


\section{Correlations Between FLAD1 Expression and DNA Mismatch Repair and Methylation Status}

The Sangerbox online tools, updated synchronously with dozens of databases worldwide every day, were used to analyze the relationship between FLAD1 expression and DNA mismatch repair (MMR) and DNA methyltransferases (DNMTS) status.

\section{Correlation Between FLAD1 Expression and Immune Cells in the TIMER and GEPIA Databases}

TIMER and the Sangerbox online tools were used to determine the relationship between FLAD1 expression and immune infiltration ${ }^{48}$. TIMER is a comprehensive resource for systematic analysis of immune infiltration in pan-cancer. It contains 10897 samples across 33 cancer types from TCGA. We analyzed the relationship between $F L A D 1$ expression and the abundance of all six immune infiltrating cell types, including B cells, CD4 + T cells, CD8 + T cells, neutrophils, macrophages, and dendritic cells (DCs). Tumor purity was also determined ${ }^{49}$.

To identify the potential immune infiltration subtypes, we additionally analyzed the relationship between FLAD1 expression and some immune cell markers, including those for $\mathrm{B}$ cells, $\mathrm{CD} 8+\mathrm{T}$ cells, $\mathrm{T}$ cells (general), M1 and M2 macrophages, monocytes, tumor-associated macrophages (TAMs), neutrophils, natural killer (NK) cells, DCs, T helper 1 (Th1), 2 (Th2), and 17 (Th17) cells, follicular helper T (Tfh) cells, regulatory $\mathrm{T}$ cells (Tregs), and exhausted $\mathrm{T}$ cells as previously reported ${ }^{50,51}$.

GEPIA is an online database with 9736 tumors and 8587 normal tissue samples from TCGA and the Genotype-Tissue Expression (GTEx) projects ${ }^{52}$. We used GEPIA to study the correlation between FLAD1 expression and immune infiltration gene markers and o confirm the TIMER results.

\section{Statistical Analysis}

The results generated in OncoMine are presented with fold changes, gene ranks, and their $P$-values as determined by $t$-tests. The log-rank test was used to calculate the HR and log-rank $P$-value in the KaplanMeier Plotter to compare survival curves. PrognoScan was used to calculate the HR and Cox $P$-value with a univariate Cox regression model. The gene expression correlation was evaluated by Spearman's rank correlation coefficient. Differences with a $P<0.05$ were considered statistically significant.

\section{Results}

\section{FLAD1 mRNA Expression Level in Pan-Cancer}

FLAD1 expression is higher in bladder, brain, breast, cervical, colorectal, gastric, kidney, liver, lung, and ovarian cancers and leukemia, lymphoma, and myeloma (Fig. 1A). We found no cancer in which FLAD1 expression in tumor tissue was lower than in the normal tissue. Detailed information on FLAD1 mRNA expression in pan-cancer is summarized in Table S1. FLAD1 mRNA expression level was in the top $1 \%$ in BRCA. 
The TIMER database was used to analyze single gene expression in pan-cancer in relation to FLAD1. The differential expression of FLAD1 between cancer and normal tissues is shown in Fig. 1B. BRCA had higher FLAD1 expression than the other cancer types.

\section{FLAD1 Prognostic Value in Pan-Cancer}

We used PrognoScan and Kaplan-Meier Plotter for a double validation exploring the relationship between FLAD1 expression and prognosis in pan-cancer. High FLAD1 expression influenced survival in seven cancers (lung, breast, skin, colorectal, head and neck, bladder, and blood) in the PrognoScan database. Increased $F L A D 1$ expression had a protective role in colorectal and head and neck cancer, while it was negatively associated with survival prognosis in the other cancer types (breast, lung, skin, brain, and bladder). However, the Kaplan-Meier Plotter showed that prognosis was not associated with FLAD1 expression in bladder, colorectal, lung, and head and neck cancer. Data on skin and blood cancers was absent from this database. Detailed information on these cancer cohorts and FLAD1 expression in PrognoScan and Kaplan-Meier Plotter is presented in Table S2 and Figures S2 and S3. Using FLAD1 median expression level as a standard, analysis of the BRCA cohorts in PrognoScan and Kaplan-Meier Plotter showed that increased FLAD1 expression was associated with poor OS, RFS, and disease metastasis-free survival (DMFS), which presented in Fig. 2.

\section{Increased FLAD1 expression is Correlated with poor BRCA Prognosis}

After finding that high FLAD1 expression was associated with poor BRCA prognosis, we performed a subgroup analysis of FLAD1 expression and survival using the UALCAN database. The data were stratified by clinical characteristics, including sample type, sex, age, race, major molecular classification, nodal metastasis status, and clinical stage (Fig. 2A-G). Subgroup analysis showed that sex did not influence FLAD1 expression in tumor tissue (Fig. 2C). However, FLAD1 expression was higher in the 21-40-year-old group than in the other age groups analyzed (Fig. 2B). The FLAD1 expression in African-Americans was higher than in Caucasians (Fig. 2D). The luminal BRCA subtype had lower FLAD1 expression than other subtypes (Fig. 2E), and BRCA patients with lymph node metastases had significantly higher FLAD1 expression than normal tissues, suggesting that FLAD1 might affect BRCA patients by increasing lymph node metastasis (Fig. 2F).

We also performed a survival analysis based on different pathological characteristics in the Kaplan-Meier Plotter (Table S3). The results showed that triple-negative BRCA $(P=0.0348)$ had poorer RFS, and luminal A-type BRCA had poor RFS and OS ( $P=0.0015$ and $P=0.0044$, respectively) when $F L A D 1$ expression was high. In BRCA patients negative for lymph node metastasis, high FLAD1 expression was also associated with a poor OS, indicating that FLAD1 expression level detection could improve the prognostic accuracy in lymph node-negative patients.

\section{FLAD1 Co-expression Networks in BRCA}

We analyzed the FLAD1 co-expression model in the BRCA cohort in the LinkedOmics database to explore FLAD1 biological significance. FLAD1 was significantly correlated with 9733 genes (black dots in Fig. 4A), 
of which 4,883 were negatively correlated ${ }^{9}$ and 4850 were positively correlated (red). Heat maps of the top 50 genes positively and negatively correlated with FLAD1 are presented in Figs. 4B and $4 \mathrm{C}$, respectively. Information on the co-expressed genes is detailed in Table S4.

The KEGG pathway analysis results showed that the co-expressed genes were enriched in the proteasome, RNA degradation, aminoacyl-tRNA biosynthesis, RNA transport, and more (Fig. 4D). GO-BP analysis showed that enrichment was mainly in the tRNA metabolic process, mitochondrial gene expression, telomere organization, deoxyribonucleotide metabolic process, and others (Fig. 4E). These results indicated that FLAD1 might have an extensive effect on the genome replication, transcription, and repair systems.

We further analyzed the FLAD1 network regulators in BRCA, including kinases, miRNA, and transcription factors enrichment (Table 1). We found no significant kinase enrichment among genes co-expressed with FLAD1 (Table S5). Among the miRNAs co-expressed with FLAD1, AAGTCA, miR-422B, miR-422A; AAGCACA, miR218; CTCTAGA, miR526C, miR518F, miR526A; TCCCCAC, miR491; ATCTTGC, miR31 are significant miRNAs associated with FLAD1 and negatively expressed in BRCA (Table S6). The serum response factor (SRF) transcription factor family, including V\$SRF_C, V\$SRF_Q4, V\$SRF_Q5_01, and V\$SRF_Q6, was the most highly enriched among the genes co-expressed with FLAD1 (Table S7).

\section{FLAD1 Expression is Associated with MMR in BRCA}

We analyzed DNA methylation and repair system status to explore the relationship between FLAD1 expression and DNA genome activity. DNMTs are essential for genome integrity in humans. Promoter hypermethylation inhibits gene expression, while methylation of the gene body contributes to its expression ${ }^{10,11}$. Meanwhile, gene body DNA methylation in cancer tissues occurs more frequently than in the promoters ${ }^{12,13}$. The levels of DNMT1 $(\mathrm{R}=0.21, P<0.001)$, DNMT2 $(\mathrm{R}=0.08, P=0.013)$, DNMT3A $(\mathrm{R}=$ $0.32, P<0.001)$, and DNMT3B $(\mathrm{R}=0.33, P<0.001)$ were all positively correlated with $F L A D 1$ expression in BRCA (Fig. 5B).

Expression of the four MMR genes, $M L H 1, M S H 2, M S H 6$, and $P M S 2$, and epithelial cell adhesion molecule (EpCAM), a transmembrane glycoprotein, is crucial for cell migration and metastasis. The relationship between FLAD1 expression and the mutation status of the MMR genes was analyzed by the Sangerbox online tools. The results showed that higher mutation rates of $M L H 1(P<0.05), M S H 2(P<0.0001), M S H 6$ $(P<0.0001)$, and EpCAM $(P<0.0001)$ were significantly correlated with $F L A D 1$ expression in BRCA (Fig. 5A).

\section{FLAD1 Expression is Associated with Immune Infiltration in BRCA}

The expression status of MMR and DNMTs was reported to be correlated with tumor-infiltrating lymphocytes $3,14,15$. TIL is an independent predictor that can guide survival and improve treatment in various cancers ${ }^{16,17}$. Our results showed that $F L A D 1$ expression was negatively correlated with immune cell infiltration in many cancer types (Fig. 6A). Furthermore, high FLAD1 expression was positively 
associated with BRCA tumor infiltration purity $(\mathrm{R}=0.131, P<0.001)$, and negatively associated with infiltration by CD8 $+\mathrm{T}$ cells $(\mathrm{R}=-0.264, P<0.001)$, neutrophils $(\mathrm{R}=-0.128, P<0.001)$, macrophages $(\mathrm{R}=$ $-0.255, P<0.001)$, and DCs $(\mathrm{R}=-0.136, P<0.001$; Fig. 6B). No association was found between $F L A D 1$ expression and the infiltrating levels of $\mathrm{B}$ cells and CD4 + T cells. These results suggest that FLAD1 might affect survival by influencing the immune infiltration into BRCA.

\section{Immune Markers Correlation with FLAD1 Expression in BRCA}

The results, adjusted by tumor purity in the TIMER database, indicated a strong correlation between FLAD1 expression and immune markers present on macrophages, monocytes, and NK cells in BRCA (Table 2). The NOS2 and TLR4 of M1 macrophages, MRC1 and PPARG of M2 macrophages, PARK2 and CSF1R of monocytes, CD7 and KIR2DL4 of NK cells, and CD1C, HLA-DPA1, and ICAM1 of DCs were specifically correlated with FLAD1 expression in BRCA ( $P<0.001$; Figure S3). Therefore, we used the GEPIA database to analyze these markers and their correlation with FLAD1 expression in BRCA tumor tissues. The results indicated that FLAD1 expression was mainly associated with macrophage infiltration into tumor tissue (Table 2). Furthermore, PPARG, a protective factor, was negatively correlated with FLAD1 expression. Treg gene marker FOXP3 and Exhausted T cell marker LAG3 were significantly and positively correlated with FLAD1 expression.

\section{Discussion}

In this study, we analyzed the differential expression of FLAD1 between tumor and normal tissues in pancancer. The results showed that FLAD1 was up-regulated in bladder, breast, cervical, colorectal, liver, and lung cancers (Fig. 1). Due to differences in data collection and analysis methods, FLAD1 expression differed in various cancer types between the databases. However, consistent FLAD1 expression trends were found in these databases for bladder, breast, colorectal, liver, and lung. Increased FLAD1 expression was associated with poor survival in most cancer types (e.g., bladder, breast, and lung), while it correlated with superior survival in colorectal and head and neck. Increased FLAD1 expression is correlated with worse BRCA survival. The subgroup survival analysis showed that FLAD1 expression was higher in young (21-40-year-old) and African-American patients, indicating poor prognosis (Fig. 3A-G). Therefore, FLAD1 could be an independent negative prognostic factor associated with poor survival in BRCA (Fig. 2A-F).

The co-expression analysis revealed a potential mechanism of how FLAD1 affected the prognosis in BRCA (Fig. 4). We found that FLAD1 correlated with the SRF transcription factor family network and miRNAs, including miR422A and miR31 (Table 1). The SRF family can attenuate BRCA cell apoptosis and support the survival of tumor epithelial cells $18,19,20$. Lower miR442A and higher miR31 promote tumor expansion and tumorigenesis and act as unfavorable factors affecting patients' survival ${ }^{15,21}$. Furthermore, the KEGG pathway analysis indicated that the FLAD1 mechanism in BRCA was associated with nucleic acid and protein synthesis.

MMR is an intracellular mismatch repair mechanism. Loss of function of key genes, including $M L H 1$, MSH2, MSH6, PSM2, and EPCAM, could lead to DNA replication errors that cannot be repaired, producing 
more somatic mutations. Genomic instability, including DNA repair defects ${ }^{22}$, is one of the most common characteristics of tumor cells. MMR is involved in the process of tumor cell apoptosis due to DNA damage. The expression level of $M L H 1$ and $M S H 2$ was negatively correlated with FLAD1 due to increased mutation status, and could ultimately promote tumor cell metastasis and progression into advanced BRCA stages ${ }^{23}$. Higher expression of miR422A could affect MMR by changing the expression of $M L H 1$, thus inhibiting the regulatory feedback mechanism between MMR and miRNA expression. Reduced $M L H 1$ expression might cause tumor progression by decreasing apoptosis ${ }^{24,25,26}$. MSH6 and EpCAM are associated with poor prognosis and metastasis in BRCA ${ }^{27,28}$. The MMR results revealed that high FLAD1 expression might promote metastasis and poor prognosis by increasing the mutation rate of proteasomes and key MMR genes and participating in the transcription regulation mechanism.

DNA methylation is associated with carcinogenesis ${ }^{29}$. Ding et al. reported that $M S H 2-M S H 6$ is involved in recruiting DNMT1 to oxidative damage sites where it acts to decrease transcription and interfere with the repair process ${ }^{30}$. Down-regulated DNMT1 promotes BRCA tumorigenesis and is correlated with poor prognosis ${ }^{31,32}$. Inhibition of DNMT1 methylation can enhance estrogen receptor and BRCA type 1 (BRCA1) activity, improve chemotherapy effect, reverse cellular transformation, and block tumor growth without increasing invasiveness ${ }^{33,34}$.

Previous studies have found that TIL affects the prognosis ${ }^{17}$ and that MMR is negatively correlated with TIL ${ }^{14}$. Our TIL analysis results showed that FLAD1 expression is correlated with immune infiltration in many cancers, including BRCA. Furthermore, FLAD1 expression was significantly correlated with the macrophage and neutrophil infiltration level in BRCA (Fig. 6). The relationships between FLAD1 expression and some immune markers differed from the overall trend, suggesting a specific interaction might exist (Table 2). Increased FLAD1 expression was positively associated with tumor purity in the immune infiltration analysis. FLAD1 expression correlated with macrophages after adjusting for tumor purity, indicating that $F L A D 1$ plays a vital role in the recruitment and regulation of immune infiltration in BRCA and is associated with carcinogenesis and metastasis ${ }^{35}$. The macrophage cell marker PPARG was found to have a protective value in cancer and was negatively correlated with FLAD1 expression. Therefore, its down-regulation contributes to cancer formation and provides an appropriate microenvironment for malignant tumor cell proliferation and metastasis, resulting in poor prognosis ${ }^{36}$. PARK2 negatively regulates the EGFR/AKT/mTOR signaling pathway in monocyte in cancer. It is also negatively correlated with FLAD1 expression, leading to lymph node metastasis ${ }^{37}$. FOXP3 increased in Treg along with FLAD1 expression, negatively influencing the OS and DFS. It also promoted proliferation and metastasis by generating adenosine to down-regulate the immune function ${ }^{38,39}$. LAG3 expressed on Exhausted T cell can downregulate the function of T cells and inhibition of LAG3 can improve the response of anti-tumor T cell $^{40}$. Therefore, FLAD1 expression could be considered an unfavorable factor for BRCA patients' survival by promoting tumor cell metastasis. However, additional downstream mechanism validation tests are still needed. 
Our study had several limitations, even though we integrated information from multiple databases into our analysis. First, we only used online databases for bioinformatic analysis of the relationship between FLAD1 expression and survival, lacking In vivo and in vitro experiments. Second, although we have found that increased FLAD1 expression was associated with poor survival and immune infiltration in BRCA patients, we have no proof that $F L A D 1$ affects the patients' survival by immune infiltration. However, we currently conduct experiments on the effect of FLAD1 overexpression on BRCA prognosis and explore its downstream mechanisms.

\section{Conclusion}

According to our analysis results, FLAD1 is overexpressed in BRCA and is associated with macrophage infiltration. Increased $F L A D 1$ expression was negatively correlated with prognosis, possibly by promoting tumor cell progression and metastasis. Therefore, we think that FLAD1 could be a biomarker for BRCA diagnosis and precise clinical treatment.

\section{Abbreviations}

FLAD1: flavin adenine dinucleotide synthetase 1; BRCA: breast cancer; FADS: flavin adenine dinucleotide synthetase; FMN: flavin mononucleotide; FAD: flavin adenine dinucleotide; TIMER: tumor immune estimation resource; GEPIA: gene expression profiling interactive analysis; OS: overall survival; DFS: disease-free survival; RFS: relapse-free survival; HRs: Hazard ratios; Cls: confidence intervals; TCGA: the cancer genome atlas project; GSEA: gene set enrichment analysis; GO-BP: gene ontology-biological process; KEGG: Kyoto encyclopedia of genes and genomes; FDR: false discovery rate; MMR: mismatch repair; DNMTS: DNA methyltransferases; TAMs: tumor-associated macrophages; NK: natural killer; GTEx: genotype-tissue expression; DMFS: disease metastasis-free survival; TIL: tumor-infiltrating lymphocytes.

\section{Declarations}

\section{Ethics Statement}

Not applicable

\section{Consent for publication}

Not applicable

\section{Availability of data and materials}

The data analyzed during the current study are available in the ?? [

\section{Competing interests}

The authors declare that no competing interests. 


\section{Funding}

This study was supported by the National Natural Science Foundation of China (No. 81872459), the

Natural Science Foundation of Guangdong Province (No. 2018A030313666), and the Social Science and Technology Development Major Project of Dongguan (2018507150241630).

\section{Author's Contributions}

Conception, design, and acquisition of data: L.Z., J.P.D., R.T., J.Y.S., F.C., Z.Y.H., S.G.W.

Data collection, analysis, and interpretation: L.Z., J.P.D., R.T.

Manuscript draft and revision: All authors.

All authors read and approved the final manuscript.

\section{Acknowledgments}

Not applicable.

\section{References}

1. Siegel RL, Miller KD, Jemal A. Cancer statistics, 2020. CA Cancer J Clin 2020, 70(1): 7-30.

2. Niehoff P, Hey-Koch S. Lymph Node Radiotherapy Instead of Extended Axillary Surgery - the New Standard? Breast Care (Basel) 2018, 13(3): 173-175.

3. Leulliot N, Blondeau K, Keller J, Ulryck N, Quevillon-Cheruel S, van Tilbeurgh H. Crystal structure of yeast FAD synthetase (Fad1) in complex with FAD. J Mol Biol 2010, 398(5): 641-646.

4. Fagerberg L, Hallstrom BM, Oksvold P, Kampf C, Djureinovic D, Odeberg J, et al. Analysis of the human tissue-specific expression by genome-wide integration of transcriptomics and antibody-based proteomics. Mol Cell Proteomics 2014, 13(2):397-406.

5. Balasubramaniam S, Christodoulou J, Rahman S. Disorders of riboflavin metabolism. J Inherit Metab Dis 2019, 42(4): 608-619.

6. Eeles RA, Olama AA, Benlloch S, Saunders EJ, Leongamornlert DA, Tymrakiewicz M, et al. Identification of 23 new prostate cancer susceptibility loci using the iCOGS custom genotyping array. Nat Genet 2013, 45(4): 385-391, 391e381-382.

7. Mitra R, Lee J, Jo J, Milani M, McClintick JN, Edenberg HJ, et al. Prediction of postoperative recurrence-free survival in non-small cell lung cancer by using an internationally validated gene expression model. Clin Cancer Res 2011, 17(9): 2934-2946.

8. Hu P, Pan Y, Wang C, Zhang W, Huang H, Wang J, et al. FLAD1 is up-regulated in Gastric Cancer and is a potential prediction of prognosis. Int J Med Sci 2020, 17(12): 1763-1772.

9. Rakha EA, El-Sayed ME, Green AR, Lee AH, Robertson JF, Ellis IO. Prognostic markers in triple-negative breast cancer. Cancer 2007, 109(1): 25-32. 
10. Neri F, Rapelli S, Krepelova A, Incarnato D, Parlato C, Basile G, et al. Intragenic DNA methylation prevents spurious transcription initiation. Nature 2017, 543(7643): 72-77.

11. Yang X, Han H, De Carvalho DD, Lay FD, Jones PA, Liang G. Gene body methylation can alter gene expression and is a therapeutic target in cancer. Cancer Cell 2014, 26(4): 577-590.

12. Maunakea AK, Chepelev I, Cui K, Zhao K. Intragenic DNA methylation modulates alternative splicing by recruiting MeCP2 to promote exon recognition. Cell Res 2013, 23(11): 1256-1269.

13. Ehrlich M. DNA hypermethylation in disease: mechanisms and clinical relevance. Epigenetics 2019 , 14(12): 1141-1163.

14. Xiao X, Dong D, He W, Song L, Wang Q, Yue J, et al. Mismatch repair deficiency is associated with MSI phenotype, increased tumor-infiltrating lymphocytes and PD-L1 expression in immune cells in ovarian cancer. Gynecol Oncol 2018, 149(1): 146-154.

15. Li SKH, Martin A. Mismatch Repair and Colon Cancer: Mechanisms and Therapies Explored. Trends Mol Med 2016, 22(4): 274-289.

16. Wouters MCA, Nelson BH. Prognostic Significance of Tumor-Infiltrating B Cells and Plasma Cells in Human Cancer. Clin Cancer Res 2018, 24(24): 6125-6135.

17. Stanton SE, Disis ML. Clinical significance of tumor-infiltrating lymphocytes in breast cancer. J Immunother Cancer 2016, 4: 59.

18. He H, Wei Z, Du F, Meng C, Zheng D, Lai Y, et al. Transcription of HOTAIR is regulated by RhoC-MRTF-ASRF signaling pathway in human breast cancer cells. Cell Signal 2017, 31: 87-95.

19. Wiese KE, Haikala HM, von Eyss B, Wolf E, Esnault C, Rosenwald A, et al. Repression of SRF target genes is critical for Myc-dependent apoptosis of epithelial cells. EMBO J 2015, 34(11): 1554-1571.

20. Kim T, Yang SJ, Hwang D, Song J, Kim M, Kyum Kim S, et al. A basal-like breast cancer-specific role for SRF-IL6 in YAP-induced cancer stemness. Nat Commun 2015, 6: 10186.

21. Zou Y, Chen Y, Yao S, Deng G, Liu D, Yuan X, et al. MiR-422a weakened breast cancer stem cells properties by targeting PLP2. Cancer Biol Ther 2018, 19(5): 436-444.

22. Lord CJ, Ashworth A. The DNA damage response and cancer therapy. Nature 2012, 481(7381): 287 294.

23. Malik SS, Masood N, Asif M, Ahmed P, Shah ZU, Khan JS. Expressional analysis of MLH1 and MSH2 in breast cancer. Curr Probl Cancer 2019, 43(2): 97-105.

24. Mao G, Lee S, Ortega J, Gu L, Li GM. Modulation of microRNA processing by mismatch repair protein MutLalpha. Cell Res 2012, 22(6): 973-985.

25. Hong Zhang, Burt Richards, Teresa Wilson, Michael Lloyd, Aaron Cranston, Andrew Thorburn, et al. Apoptosis Induced by Overexpression of hMSH2 or hMLH1. CANCER RESEARCH 1999, 59: 3021-3027.

26. Chen F, Arseven OK, Cryns VL. Proteolysis of the mismatch repair protein MLH1 by caspase-3 promotes DNA damage-induced apoptosis. J Biol Chem 2004, 279(26): 27542-27548.

27. Roberts ME, Jackson SA, Susswein LR, Zeinomar N, Ma X, Marshall ML, et al. MSH6 and PMS2 germline pathogenic variants implicated in Lynch syndrome are associated with breast cancer. Genet Med 2018, 20(10): 1167-1174. 
28. Hiraga T, Ito S, Nakamura H. EpCAM expression in breast cancer cells is associated with enhanced bone metastasis formation. Int J Cancer 2016, 138(7): 1698-1708.

29. Yan L, Yang X Fau - Davidson NE, Davidson NE. Role of DNA methylation and histone acetylation in steroid receptor expression in breast cancer. (1083-3021 (Print)).

30. Ding N, Bonham EM, Hannon BE, Amick TR, Baylin SB, O'Hagan HM. Mismatch repair proteins recruit DNA methyltransferase 1 to sites of oxidative DNA damage. J Mol Cell Biol 2016, 8(3): 244-254.

31. Liu H, Song Y, Qiu H, Liu Y, Luo K, Yi Y, et al. Downregulation of FOXO3a by DNMT1 promotes breast cancer stem cell properties and tumorigenesis. Cell Death Differ 2020, 27(3): 966-983.

32. Yu Z, Xiao Q, Zhao L, Ren J, Bai X, Sun M, et al. DNA methyltransferase 1/3a overexpression in sporadic breast cancer is associated with reduced expression of estrogen receptor-alpha/breast cancer susceptibility gene 1 and poor prognosis. Mol Carcinog 2015, 54(9): 707-719.

33. Chik F, Szyf M. Effects of specific DNMT gene depletion on cancer cell transformation and breast cancer cell invasion; toward selective DNMT inhibitors. Carcinogenesis 2011, 32(2): 224-232.

34. Kristensen LS, Nielsen HM, Hansen LL. Epigenetics and cancer treatment. Eur J Pharmaco/2009, 625(1-3): 131-142.

35. Sousa S, Maatta J. The role of tumour-associated macrophages in bone metastasis. J Bone Oncol 2016, 5(3): 135-138.

36. Tang W, Chen Y, Wang Y, Gu H, Chen S, Kang M. Peroxisome proliferator-activated receptor gamma (PPARG) polymorphisms and breast cancer susceptibility: a meta-analysis. Int J Clin Exp Med 2015, 8(8): 12226-12238.

37. Duan H, Lei Z, Xu F, Pan T, Lu D, Ding P, et al. PARK2 Suppresses Proliferation and Tumorigenicity in Non-small Cell Lung Cancer. Front Oncol 2019, 9: 790.

38. Peng G-L, Li L, Guo Y-W, Yu P, Yin X-J, Wang S, et al. CD8+cytotoxic and FoxP3+ regulatory T lymphocytes serve as prognostic factors in breast cancer. Am J Transl Res 2019, 11(8): 5039-5053.

39. Shou J, Zhang Z, Lai Y, Chen Z, Huang J. Worse outcome in breast cancer with higher tumorinfiltrating FOXP3+ Tregs : a systematic review and meta-analysis. BMC Cancer 2016, 16: 687.

40. Nguyen LT, Ohashi PS. Clinical blockade of PD1 and LAG3 - potential mechanisms of action. Nature Reviews Immunology 2014, 15(1): 45-56.

41. Rhodes DR, Kalyana-Sundaram S, Mahavisno V, Varambally R, Yu J, Briggs BB, et al. Oncomine 3.0: genes, pathways, and networks in a collection of 18,000 cancer gene expression profiles. Neoplasia 2007, 9(2): 166-180.

42. Mizuno H, Kitada K, Nakai K, Sarai A. PrognoScan: a new database for meta-analysis of the prognostic value of genes. BMC Med Genomics 2009, 2: 18.

43. Gyorffy B, Lanczky A, Eklund AC, Denkert C, Budczies J, Li Q, et al. An online survival analysis tool to rapidly assess the effect of 22,277 genes on breast cancer prognosis using microarray data of 1,809 patients. Breast Cancer Res Treat 2010, 123(3): 725-731.

44. Loi S, Sirtaine N, Piette F, Salgado R, Viale G, Van Eenoo F, et al. Prognostic and predictive value of tumor-infiltrating lymphocytes in a phase III randomized adjuvant breast cancer trial in node-positive 
breast cancer comparing the addition of docetaxel to doxorubicin with doxorubicin-based chemotherapy: BIG 02-98. J Clin Oncol 2013, 31(7): 860-867.

45. Chandrashekar DS, Bashel B, Balasubramanya SAH, Creighton CJ, Ponce-Rodriguez I, Chakravarthi B, et al. UALCAN: A Portal for Facilitating Tumor Subgroup Gene Expression and Survival Analyses. Neoplasia 2017, 19(8): 649-658.

46. Robertson AG, Kim J, Al-Ahmadie H, Bellmunt J, Guo G, Cherniack AD, et al. Comprehensive Molecular Characterization of Muscle-Invasive Bladder Cancer. Cell 2017, 171(3): 540-556 e525.

47. Vasaikar SV, Straub P, Wang J, Zhang B. LinkedOmics: analyzing multi-omics data within and across 32 cancer types. Nucleic Acids Res 2018, 46(D1): D956-D963.

48. Li T, Fu J, Zeng Z, Cohen D, Li J, Chen Q, et al. TIMER2.0 for analysis of tumor-infiltrating immune cells. Nucleic Acids Res 2020, 48(W1): W509-W514.

49. Aran D, Sirota M, Butte AJ. Systematic pan-cancer analysis of tumour purity. Nat Commun 2015, 6: 8971.

50. Danaher P, Warren S, Dennis L, D'Amico L, White A, Disis ML, et al. Gene expression markers of Tumor Infiltrating Leukocytes. J Immunother Cancer 2017, 5: 18.

51. Siemers NO, Holloway JL, Chang H, Chasalow SD, Ross-MacDonald PB, Voliva CF, et al. Genome-wide association analysis identifies genetic correlates of immune infiltrates in solid tumors. PLoS One 2017, 12(7): e0179726.

52. Tang Z, Li C, Kang B, Gao G, Li C, Zhang Z. GEPIA: a web server for cancer and normal gene expression profiling and interactive analyses. Nucleic Acids Res 2017, 45(W1): W98-W102.

53. Medina-Carmona E, Rizzuti B, Martin-Escolano R, Pacheco-Garcia JL, Mesa-Torres N, Neira JL, et al. Phosphorylation compromises FAD binding and intracellular stability of wild-type and cancerassociated NQ01: Insights into flavo-proteome stability. Int J Biol Macromol 2019, 125: 1275-1288.

\section{Tables}


Table 1

The Kinases miRNAs and transcription factors-target networks of FLAD1 in BRCA

BRCA.

\begin{tabular}{|c|c|c|c|}
\hline Enriched Category & Geneset & Leading Edge Number & FDR \\
\hline \multirow[t]{5}{*}{ miRNA } & AAGTCCA, MIR422B, MIR422A & 19 & 0.02411 \\
\hline & AAGCACA, MIR218 & 67 & 0.034826 \\
\hline & CTCTAGA, MIR526C, MIR518F, MIR-526A & 15 & 0.034826 \\
\hline & TCCCCAC, MIR491 & 10 & 0.040183 \\
\hline & ATCTTGC, MIR-31 & 16 & 0.043197 \\
\hline \multirow[t]{7}{*}{ Transcription factor } & V\$AP4_Q6 & 36 & 0.012268 \\
\hline & VSFOX_Q2 & 44 & 0.029254 \\
\hline & V\$SRF_Q6 & 46 & 0.030884 \\
\hline & VSSRF_C & 46 & 0.032383 \\
\hline & V\$SRF_Q4 & 39 & 0.03284 \\
\hline & V\$SRF_Q5_01 & 41 & 0.035231 \\
\hline & V\$AFP1_Q6 & 45 & 0.035527 \\
\hline
\end{tabular}


Table 2

Analysis of correlations between FLAD1 expression and related immune gene markers in the TIMER database and the GEPIA database

\begin{tabular}{|c|c|c|c|c|c|c|c|c|c|}
\hline \multirow[t]{3}{*}{ Description } & \multicolumn{5}{|l|}{ TIMER } & \multicolumn{4}{|l|}{ GEPIA } \\
\hline & \multirow[t]{2}{*}{$\begin{array}{l}\text { Gene } \\
\text { markers }\end{array}$} & \multicolumn{2}{|l|}{ None } & \multicolumn{2}{|c|}{$\begin{array}{l}\text { Purity } \\
\text { adjustment }\end{array}$} & \multicolumn{2}{|l|}{ Tumor } & \multicolumn{2}{|l|}{ Normal } \\
\hline & & Corr & $\mathbf{P}$ & Corr & $\mathbf{P}$ & Corr & $\mathbf{P}$ & Corr & $\mathbf{P}$ \\
\hline \multirow[t]{2}{*}{ B cell } & CD19 & 0.013 & $\begin{array}{l}6.72 \mathrm{E}- \\
01\end{array}$ & 0.084 & $\begin{array}{l}7.73 \mathrm{E}- \\
03\end{array}$ & & & & \\
\hline & CD79A & -0.008 & $\begin{array}{l}7.98 \mathrm{E}- \\
01\end{array}$ & 0.0075 & $\begin{array}{l}1.85 \mathrm{E}- \\
02\end{array}$ & & & & \\
\hline \multirow[t]{2}{*}{$\mathrm{CD} 8+\mathrm{T}$ cell } & CD8A & -0.039 & $\begin{array}{l}2.01 \mathrm{E}- \\
01\end{array}$ & 0.042 & $\begin{array}{l}1.85 \mathrm{E}- \\
01\end{array}$ & & & & \\
\hline & CD8B & -0.021 & $\begin{array}{l}4.85 \mathrm{E}- \\
01\end{array}$ & 0.059 & $\begin{array}{l}6.49 \mathrm{E}- \\
02\end{array}$ & & & & \\
\hline \multirow[t]{2}{*}{$\begin{array}{l}\text { T cell } \\
\text { (general) }\end{array}$} & CD3D & -0.027 & $\begin{array}{l}3.71 \mathrm{E}- \\
01\end{array}$ & 0.057 & $\begin{array}{l}7.31 \mathrm{E}- \\
02\end{array}$ & & & & \\
\hline & CD3E & -0.033 & $\begin{array}{l}2.67 \mathrm{E}- \\
01\end{array}$ & 0.053 & $\begin{array}{l}9.8 \mathrm{E}- \\
02\end{array}$ & & & & \\
\hline \multirow[t]{2}{*}{$\begin{array}{l}\text { M1 } \\
\text { Macrophage }\end{array}$} & Nos2 & -0.006 & $\begin{array}{l}8.35 \mathrm{E}- \\
01\end{array}$ & -0.101 & $\begin{array}{l}1.83 \mathrm{E}- \\
01\end{array}$ & -0.033 & 0.28 & -0.0093 & 0.92 \\
\hline & TLR4 & -0.213 & $\begin{array}{l}8.8 \mathrm{E}- \\
13\end{array}$ & -0.171 & $\begin{array}{l}5.56 \mathrm{E}- \\
08\end{array}$ & -0.27 & $\begin{array}{l}3.1 \mathrm{E}- \\
19\end{array}$ & -0.05 & 0.6 \\
\hline \multirow[t]{2}{*}{$\begin{array}{l}\text { M2 } \\
\text { Macrophage }\end{array}$} & MRC1 & -0.15 & $\begin{array}{l}5.96 \mathrm{E}- \\
07\end{array}$ & -0.108 & $\begin{array}{l}6.87 \mathrm{E}- \\
04\end{array}$ & -0.2 & $\begin{array}{l}2.6 \mathrm{E}- \\
11\end{array}$ & 0.024 & 0.8 \\
\hline & PPARG & -0.168 & $\begin{array}{l}2.08 \mathrm{E}- \\
08\end{array}$ & -0.138 & $\begin{array}{l}1.3 \mathrm{E}- \\
05\end{array}$ & -0.17 & $\begin{array}{l}2.9 \mathrm{E}- \\
08\end{array}$ & -0.016 & 0.87 \\
\hline \multirow[t]{2}{*}{ Monocyte } & PARK2 & -0.258 & $\begin{array}{l}3.65 \mathrm{E}- \\
18\end{array}$ & -0.252 & $\begin{array}{l}7.4 \mathrm{E}- \\
16\end{array}$ & -0.28 & $\begin{array}{l}2.6 \mathrm{E}- \\
20\end{array}$ & 0.076 & 0.43 \\
\hline & CSF1R & -0.15 & $\begin{array}{l}1.9 \mathrm{E}- \\
08\end{array}$ & -0.126 & $\begin{array}{l}7.12 \mathrm{E}- \\
05\end{array}$ & -0.19 & $3 E-10$ & 0.22 & 0.019 \\
\hline \multirow[t]{2}{*}{ TAM } & CCL2 & -0.045 & $\begin{array}{l}1.34 \mathrm{E}- \\
01\end{array}$ & 0.006 & $\begin{array}{l}8.48 \mathrm{E}- \\
01\end{array}$ & & & & \\
\hline & IL10 & -0.039 & $\begin{array}{l}1.92 \mathrm{E}- \\
01\end{array}$ & 0.005 & $\begin{array}{l}8.85 \mathrm{E}- \\
01\end{array}$ & & & & \\
\hline
\end{tabular}

Corr, correlation coefficient; Tumor, correlation analysis in BRCA tumor of TCGA; Normal, correlation analysis in BRCA normal of TCGA; TAM, tumor-associated-macrophage; NK, nature killer cell; DC, dendritic cell; Th, T helper cell; Tfh, follicular helper T cell; Treg, regulatory T cell.

${ }^{*} \mathrm{P}<0.01 ;{ }^{* * \mathrm{P}}<0.001 ;{ }^{*} \mathrm{P}<0.0001$. 


\begin{tabular}{|c|c|c|c|c|c|c|c|c|c|}
\hline \multirow[t]{2}{*}{ Neutrophils } & CCR7 & -0.002 & $\begin{array}{l}9.57 \mathrm{E}- \\
01\end{array}$ & 0.072 & \multicolumn{5}{|l|}{$\begin{array}{l}2.32 \mathrm{E}- \\
02\end{array}$} \\
\hline & CD44 & -0.164 & $\begin{array}{l}4.34 \mathrm{E}- \\
08\end{array}$ & -0.157 & $\begin{array}{l}6.83 \mathrm{E}- \\
07\end{array}$ & & & & \\
\hline \multirow[t]{2}{*}{ NK cells } & CD7 & 0.066 & $\begin{array}{l}2.96 \mathrm{E}- \\
02\end{array}$ & 0.156 & $\begin{array}{l}8.13 \mathrm{E}- \\
07\end{array}$ & 0.062 & 0.041 & 0.24 & 0.011 \\
\hline & KIR2DL4 & 0.057 & $\begin{array}{l}6.01 \mathrm{E}- \\
02\end{array}$ & 0.104 & $\begin{array}{l}9.92 \mathrm{E}- \\
04\end{array}$ & 0.054 & 0.077 & 0.13 & 0.16 \\
\hline \multirow[t]{3}{*}{ DCs } & CD1C & -0.166 & $\begin{array}{l}3.24 \mathrm{E}- \\
08\end{array}$ & -0.123 & $\begin{array}{l}1.02 \mathrm{E}- \\
04\end{array}$ & -0.17 & $\begin{array}{l}9.2 \mathrm{E}- \\
09\end{array}$ & 0.049 & 0.61 \\
\hline & $\begin{array}{l}\text { HLA- } \\
\text { DPA1 }\end{array}$ & -0.157 & $\begin{array}{l}1.67 \mathrm{E}- \\
07\end{array}$ & -0.112 & $\begin{array}{l}4.01 \mathrm{E}- \\
04\end{array}$ & -0.18 & $\begin{array}{l}1.2 \mathrm{E}- \\
09\end{array}$ & 0.14 & 0.15 \\
\hline & ICAM1 & 0.084 & $\begin{array}{l}5.51 \mathrm{E}- \\
03\end{array}$ & 0.158 & $\begin{array}{l}5.26 \mathrm{E}- \\
07\end{array}$ & 0.06 & 0.05 & 0.19 & 0.047 \\
\hline \multirow[t]{2}{*}{ Th1 cells } & IL12RB2 & 0.163 & $\begin{array}{l}5.19 \mathrm{E}- \\
08\end{array}$ & 0.203 & $\begin{array}{l}1.08 \mathrm{E}- \\
10\end{array}$ & & & & \\
\hline & TNF & 0.129 & $\begin{array}{l}1.85 \mathrm{E}- \\
05\end{array}$ & 0.146 & $\begin{array}{l}3.55 \mathrm{E}- \\
06\end{array}$ & & & & \\
\hline \multirow[t]{2}{*}{ Th2 cells } & CCR3 & 0.019 & $\begin{array}{l}5.24 \mathrm{E}- \\
01\end{array}$ & 0.062 & $\begin{array}{l}5.03 \mathrm{E}- \\
02\end{array}$ & & & & \\
\hline & STAT6 & 0.008 & $\begin{array}{l}7.91 \mathrm{E}- \\
01\end{array}$ & 0.02 & $\begin{array}{l}5.37 \mathrm{E}- \\
01\end{array}$ & & & & \\
\hline \multirow[t]{2}{*}{ Tfh cells } & ICOS & 0.06 & $\begin{array}{l}4.61 \mathrm{E}- \\
02\end{array}$ & 0.126 & $\begin{array}{l}6.36 \mathrm{E}- \\
05\end{array}$ & & & & \\
\hline & BCL-6 & -0.152 & $\begin{array}{l}3.97 \mathrm{E}- \\
07\end{array}$ & -0.158 & $\begin{array}{l}5.43 E- \\
07\end{array}$ & & & & \\
\hline \multirow[t]{2}{*}{ Th17 cells } & IL-23A & 0.077 & $\begin{array}{l}1.04 \mathrm{E}- \\
02\end{array}$ & 0.113 & $\begin{array}{l}3.55 \mathrm{E}- \\
04\end{array}$ & & & & \\
\hline & STAT3 & 0.012 & $\begin{array}{l}6.92 \mathrm{E}- \\
01\end{array}$ & -0.003 & $\begin{array}{l}9.14 \mathrm{E}- \\
01\end{array}$ & & & & \\
\hline Treg & FOXP3 & 0.042 & $\begin{array}{l}1.62 \mathrm{E}- \\
01\end{array}$ & 0.108 & $\begin{array}{l}6.82 \mathrm{E}- \\
04\end{array}$ & & & & \\
\hline \multicolumn{10}{|c|}{$\begin{array}{l}\text { Corr, correlation coefficient; Tumor, correlation analysis in BRCA tumor of TCGA; Normal, correlation } \\
\text { analysis in BRCA normal of TCGA; TAM, tumor-associated-macrophage; NK, nature killer cell; DC, } \\
\text { dendritic cell; Th, T helper cell; Tfh, follicular helper T cell; Treg, regulatory T cell. }\end{array}$} \\
\hline$\star P<0.01 ; * \star P$ & $001 ; * P$ & 0001. & & & & & & & \\
\hline
\end{tabular}




\begin{tabular}{|c|c|c|c|c|c|}
\hline & TGFB1 & -0.195 & $\begin{array}{l}7.43 \mathrm{E}- \\
11\end{array}$ & -0.154 & $\begin{array}{l}1.05 \mathrm{E}- \\
06\end{array}$ \\
\hline \multirow[t]{3}{*}{$\begin{array}{l}\text { Exhausted T } \\
\text { cells }\end{array}$} & CTLA4 & 0.06 & $\begin{array}{l}4.74 \mathrm{E}- \\
02\end{array}$ & 0.13 & $\begin{array}{l}3.79 \mathrm{E}- \\
05\end{array}$ \\
\hline & GZMB & 0.075 & $\begin{array}{l}1.32 \mathrm{E}- \\
02\end{array}$ & 0.142 & $\begin{array}{l}6.52 \mathrm{E}- \\
06\end{array}$ \\
\hline & LAG3 & 0.107 & $\begin{array}{l}4.01 \mathrm{E}- \\
04\end{array}$ & 0.145 & $\begin{array}{l}4.71 \mathrm{E}- \\
06\end{array}$ \\
\hline \multicolumn{6}{|c|}{$\begin{array}{l}\text { Corr, correlation coefficient; Tumor, correlation analysis in BRCA tumor of TCGA; Normal, correlation } \\
\text { analysis in BRCA normal of TCGA; TAM, tumor-associated-macrophage; NK, nature killer cell; DC, } \\
\text { dendritic cell; Th, T helper cell; Tfh, follicular helper T cell; Treg, regulatory T cell. }\end{array}$} \\
\hline \multicolumn{6}{|c|}{$\star P<0.01 ; * \star P<<0.001 ; * P<0.0001}$. \\
\hline
\end{tabular}

\section{Figures}
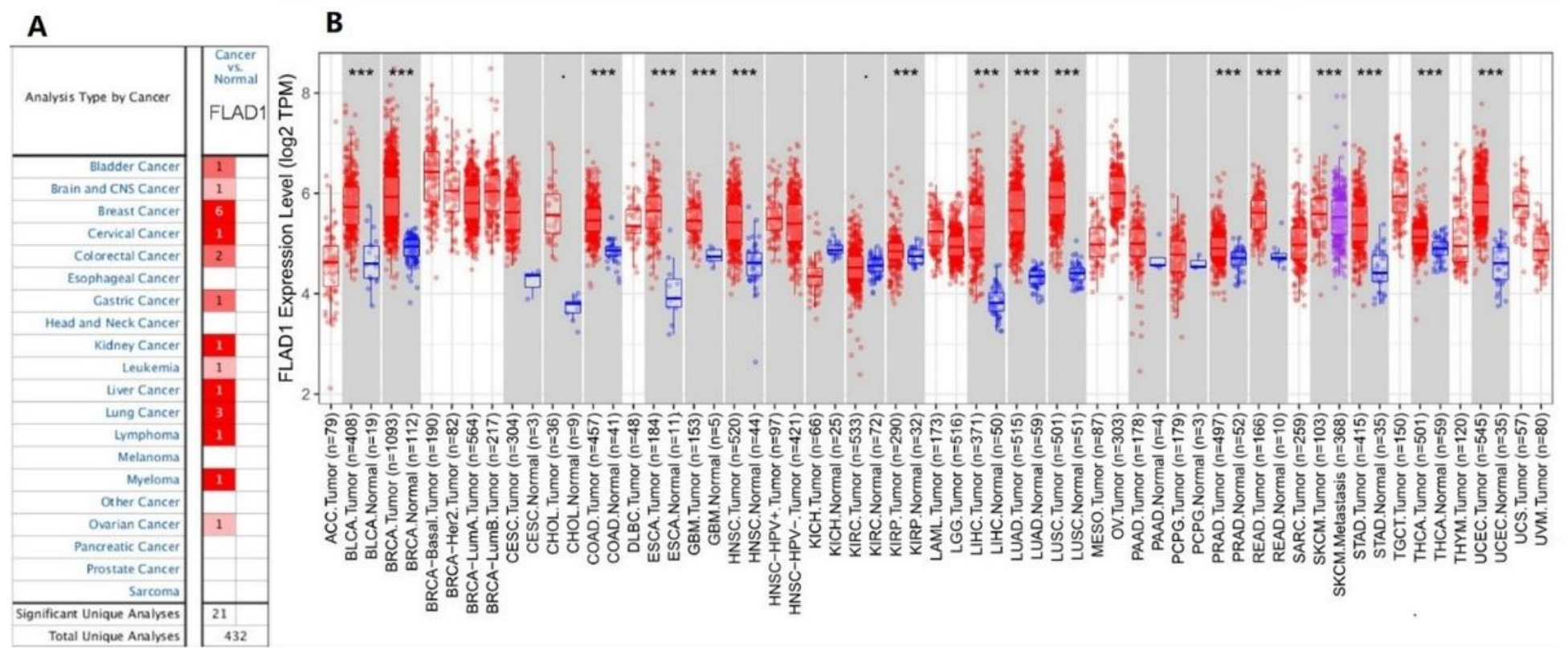

\section{Figure 1}

FLAD1 expression in human cancers. (A) A comparison of FLAD1 expression in cancer and normal tissues of different cancer types in the OncoMine (A) and TIMER (B) databases. FLAD1, flavin adenine dinucleotide synthetase 1; TIMER, Tumor Immune Estimation Resource. 
A

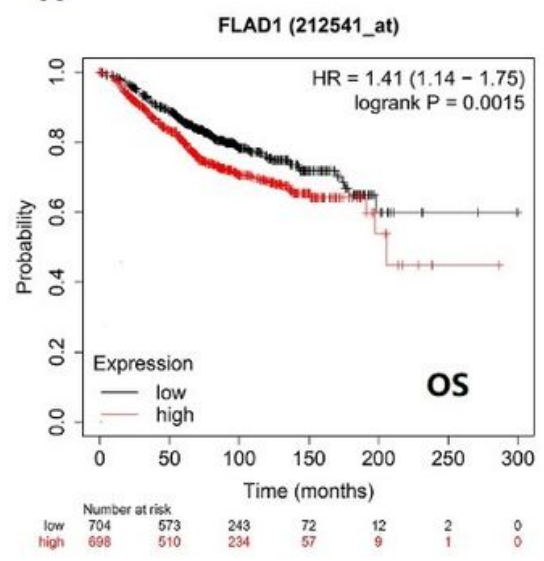

D Breast cancer GSE1456-GPL96 OS $\mathrm{HR}=2.70[1.32-5.55] \operatorname{Cox} P=0.007$

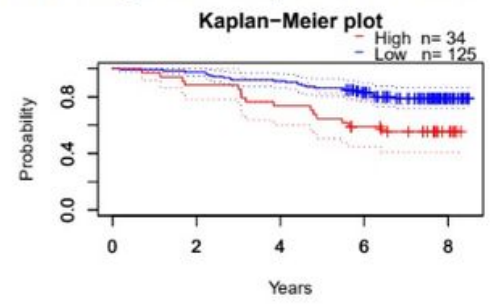

B

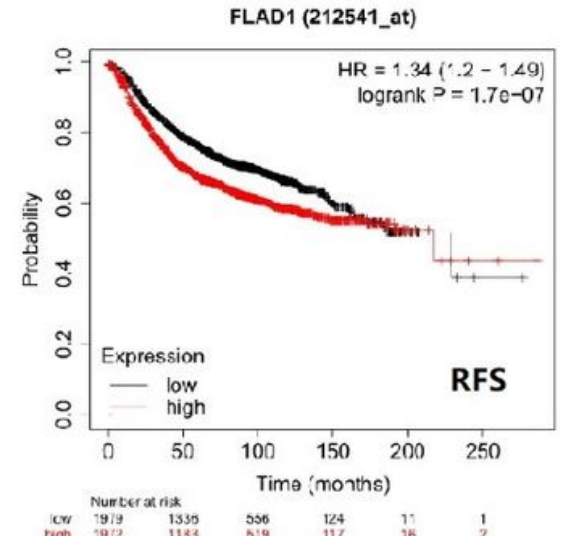

E Breast cancer GSE12276 RFS $\mathrm{HR}=1.56[1.08-2.25] \operatorname{Cox} P=0.017$

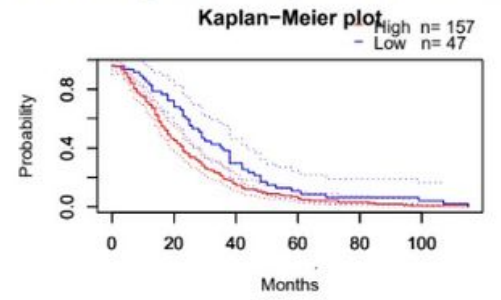

C

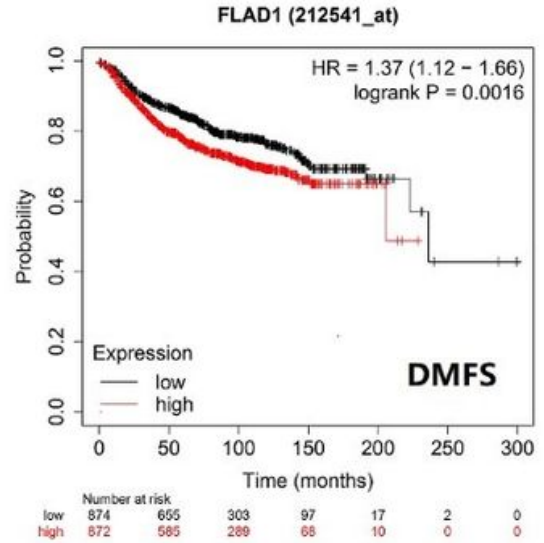

F Breast cancer GSE9195 DMFS

$\mathrm{HR}=4.03[1.20-13.58]$ Cox $P=0.025$

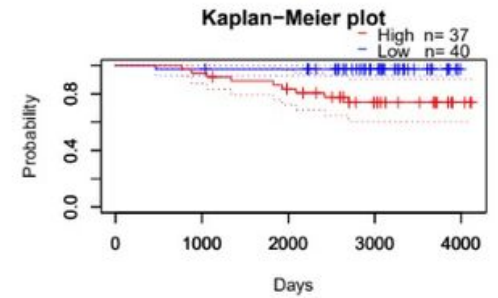

Figure 2

Kaplan-Meier survival curves for FLAD1 expression with different BRCA endpoints in the Kaplan-Meier Plotter 53 and PrognoScan database (D-F). High FLAD1 expression was associated with a worse survival in the Kaplan-Meier Plotter: (A) OS (HR [95\% Cl] = 1.41 [1.14-1.49], $\mathrm{P}=0.0015)$; (B) RFS (HR [95\% Cl] $=1.34$ [1.20-1.49], $\mathrm{P}=1.7 \mathrm{e}-07) ;(\mathrm{C})$ DMFS (HR [95\% Cl] = 1.37 [1.12-1.66], $\mathrm{P}=0.0016)$; and the PrognoScan database: (D) OS (HR [95\% Cl] = 2.70 [1.32-5.55], $\mathrm{P}=0.007)$; (E) RFS (HR [95\% Cl] = 1.56 [1.08-2.25], $\mathrm{P}=$ 0.017); (F) DMFS (HR [95\% Cl] = 4.03 [1.20-13.58], $\mathrm{P}=0.025)$. OS, overall survival; $R F S$, relapse free survival; DMFS, disease metastasis free survival; BRCA, breast cancer; FLAD1, flavin adenine dinucleotide synthetase 1. 

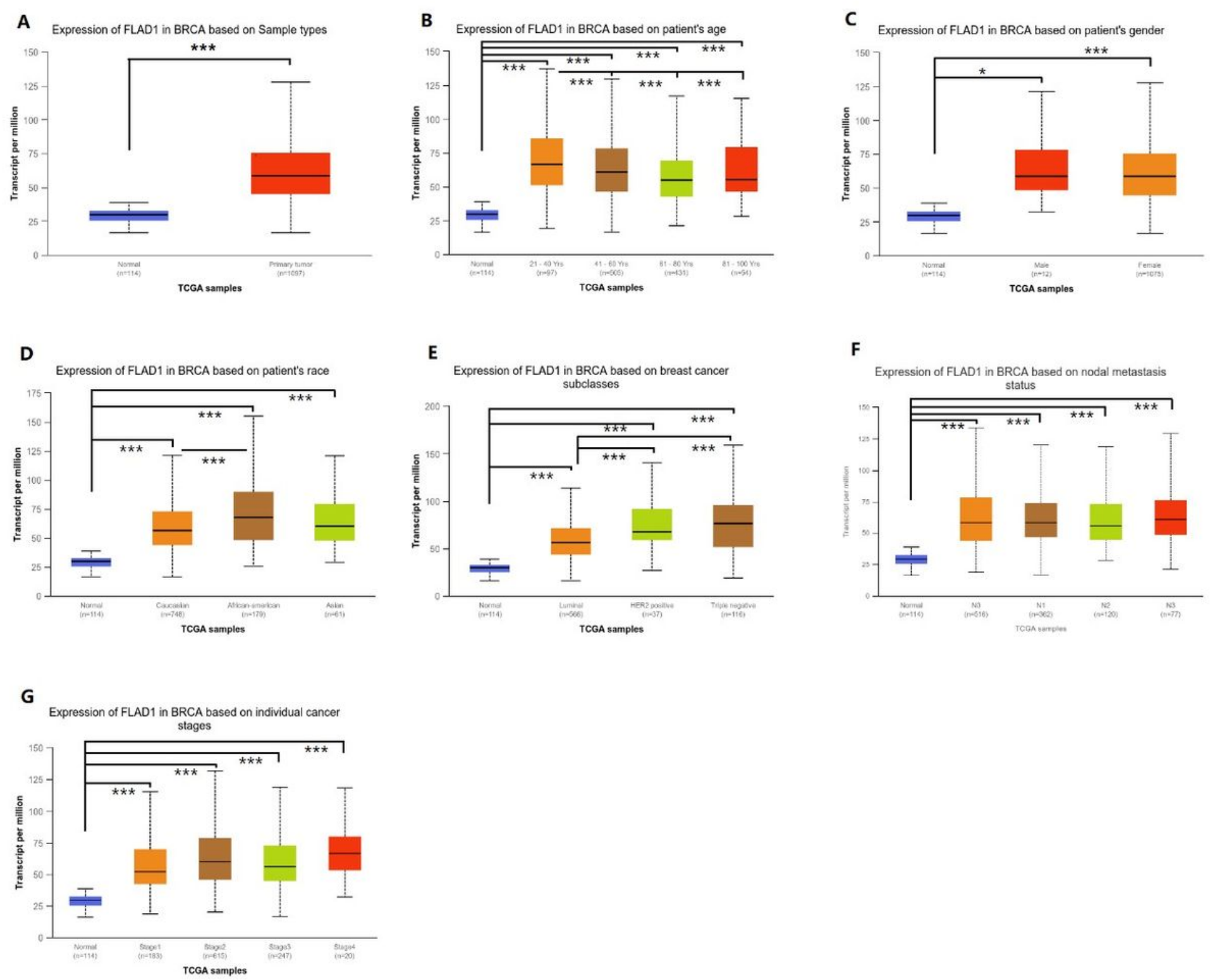

Figure 3

FLAD1 expression level in BRCA subtypes, stratified by sample type, age, sex, ethnicity, subclasses of BRCA, nodal status, and stage in the UALCAN database. The box-and-whisker plots show FLAD1 relative expression in BRCA samples: (A) in normal and BRCA samples; $(B)$ in normal tissues of all ages and BRCA patients aged 21-40, 41-60, 61-80, or 81-100 years; (C) in normal tissues of both sexes and male or female BRCA patients; (D) in normal and BRCA tissues in Caucasian, African-American, and Asian patients; (E) in normal tissues and luminal, HER2-positive, and triple-negative BRCA subtypes; (F) in normal tissues and BRCA with nodal metastasis status of N0, 1, 2, or 3; (G) in normal tissues and BRCA patients at disease stages $1,2,3$, and 4 . The central line represents the median expression level, and the box edges are the 25th and 75th percentiles. Differences between subgroups in FLAD1 expression level were estimate by ttest $\left({ }^{\star} P<0.05,{ }^{*} P<<0.01, * \star * P<0.001\right)$. BRCA, breast cancer; FLAD1, flavin adenine dinucleotide synthetase 1. 
A

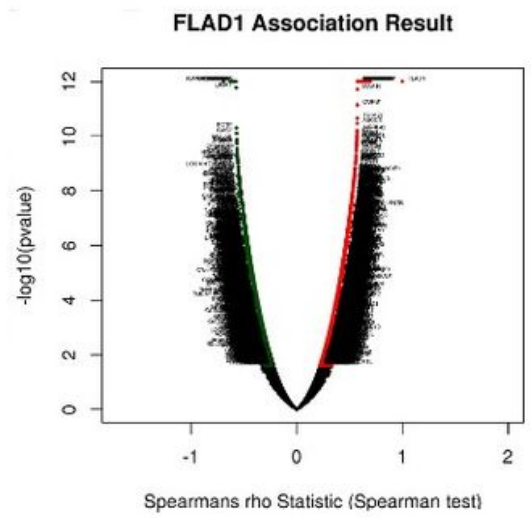

D

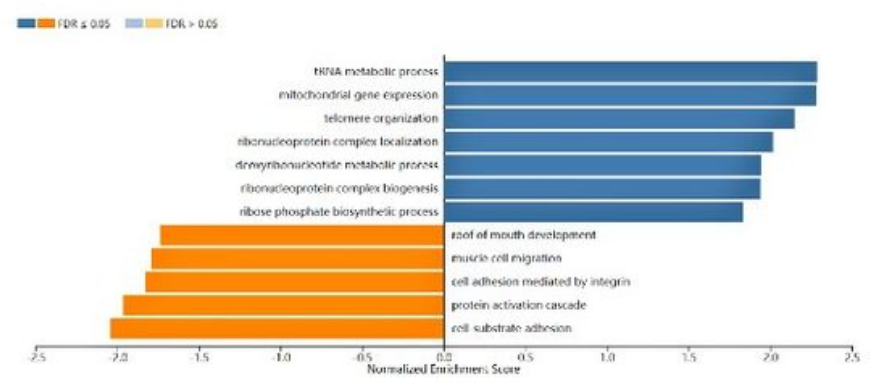

C

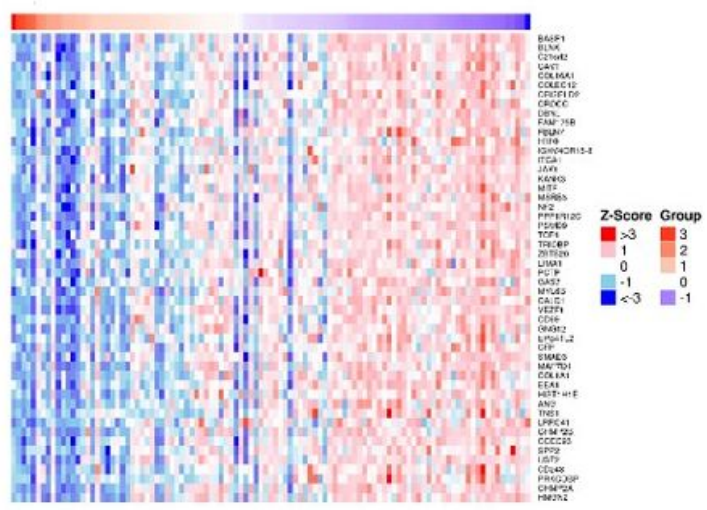

E

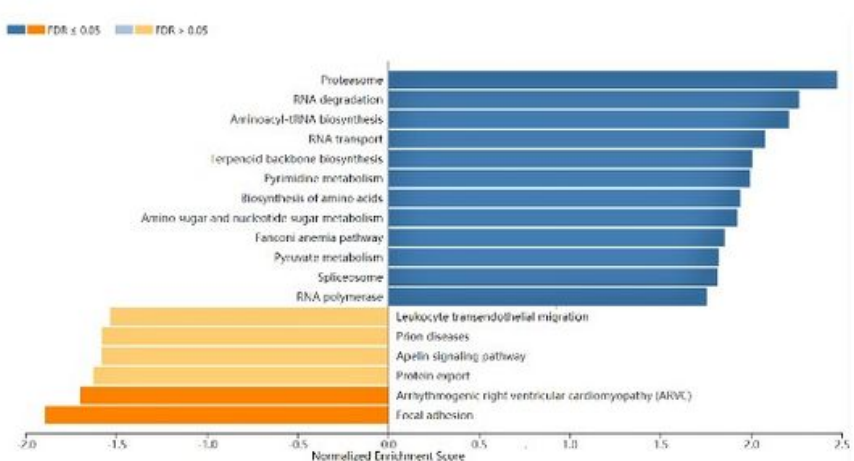

Figure 4

Genes are co-expressed with FLAD1 in BRCA in the LinkedOmics database. (A) Genes highly correlated with FLAD1 as identified by Spearman's rank correlation coefficient test in the BRCA cohort. (B) A heat map showing the top 50 genes positively correlated with FLAD1. (C) A heat map showing the top 50 genes negatively correlated with FLAD1. Red means a positive correlation, and blue means a negative correlation. (D) Significantly enriched KEGG pathways related to FLAD1 in the BRCA cohort. (E) Significantly enriched $\mathrm{GO}$ analysis Biological Process terms of FLAD1 in the BRCA cohort. BRCA, breast cancer; FLAD1, flavin adenine dinucleotide synthetase 1; KEGG, Kyoto Encyclopedia of Genes and Genomes; GO, gene ontology. 
A

$$
\text { BRCA }
$$

\begin{tabular}{lllllllll}
\multicolumn{3}{c}{ Pearson's rho } & \multicolumn{8}{c}{$-\log 10(\mathrm{p}$ value $)$} \\
\hline-0.45 & -0.23 & 0 & 0.23 & 0.450 & 4.71 & 9.43 & 14.14 & 18.85
\end{tabular}

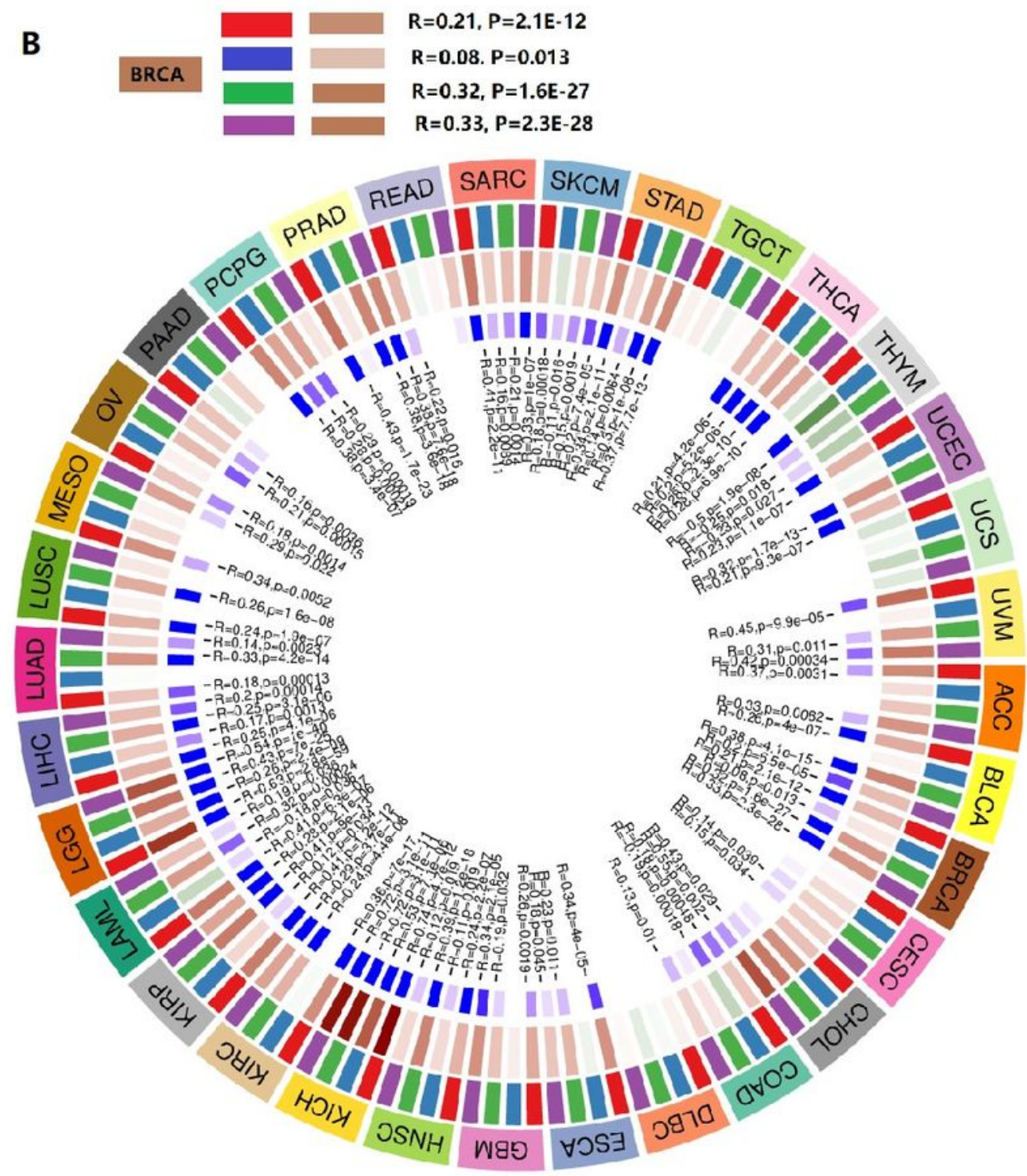

\section{Figure 5}

Relationship between FLAD1 expression in BRCA and the expression of MMR and methyltransferase genes related to DNA repair in pan-cancer. (A) The Cancer Genome Atlas 46 expression profile data of five MMRs genes MLH1, MSH2, MSH6, PMS2, and EPCAM were used to evaluate the relationship between mutations and gene expression. (B) The correlations between the expression of FLAD1 and four methyltransferases were analyzed. We studied DNMT1 (red), DNMT2 (blue), DNMT3A 9, and DNMT3B (violet). MMR, 
mismatch repair; DNMT, DNA methyltransferase; BRCA, breast cancer; FLAD1, flavin adenine dinucleotide synthetase 1.

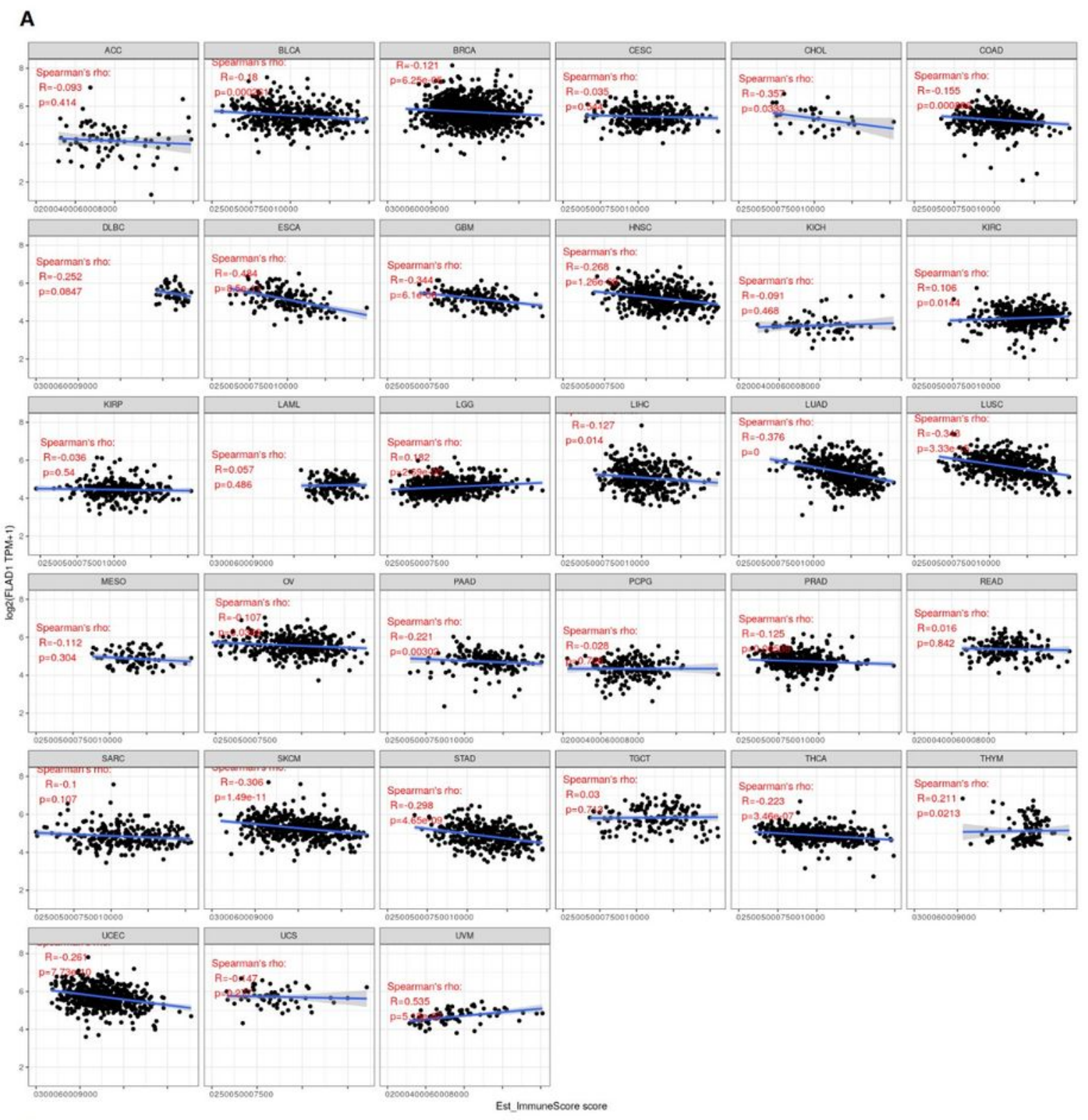

B

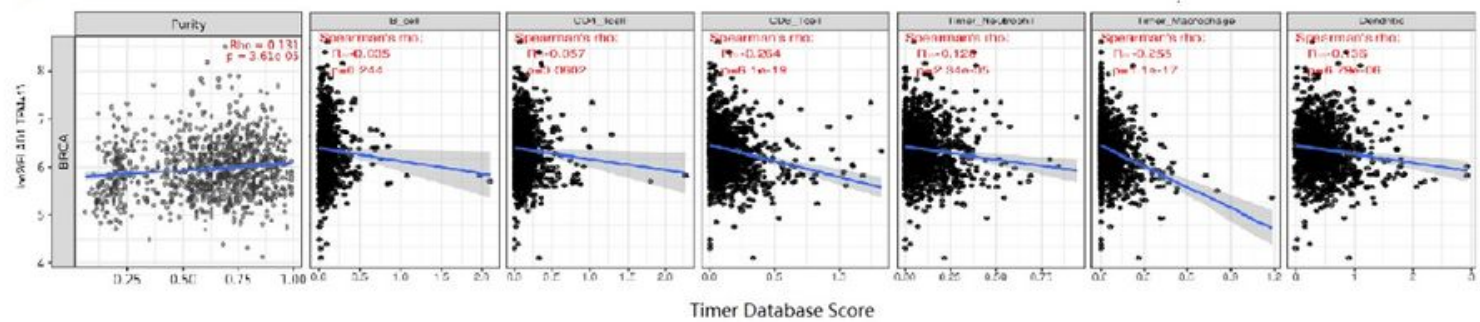

Figure 6

FLAD1 gene expression correlation with immune infiltration levels in different cancer types and the immune system cell populations in BRCA. (A) FLAD1 expression correlates with immune infiltration in many cancer types. (B) FLAD1 expression positively correlates with tumor purity and negatively correlates 
with infiltration levels of CD8+ T cells, neutrophils, macrophage, and dendritic cells in BRCA. The correlations between the gene expression and the immune cell scores were analyzed separately. BRCA, breast cancer; FLAD1, flavin adenine dinucleotide synthetase 1.

\section{Supplementary Files}

This is a list of supplementary files associated with this preprint. Click to download.

- SupplementaryTables.docx

- SupplementaryFigure.docx 